\title{
Variations of the Crustal Structure of Arabia
}

\author{
T.A. MOKHTAR \\ Department of Geophysics, Faculty of Earth Sciences \\ King Abdulaziz University \\ P.O. Box 80206, Jeddah 21589, Saudi Arabia
}

Received: 19/1/2003 Revised: 23/9/2003 Accepted: 29/10/2003

\begin{abstract}
Data from the broadband seismic stations deployed in Saudi Arabia during 1996 made it possible to study the variation of surface wave dispersion of the Arabian plate as a function of azimuth. Careful selection of the paths from earthquakes associated with the boundaries of the Arabian plate was made, and the group velocities of the fundamental mode of both Love and Rayleigh waves along these paths were studied. Results show that the Arabian plate is characterized mainly by two different sets of similar group velocity curves that are related to the two major geological units, the Arabian shield and the Arabian platform. The group velocities along paths that traverse the eastern, northeastern, and northwestern regions of Arabia are found to be representative of the Arabian platform geologic province, and are slower than those along the Gulf of Aqaba, the southeastern and the southwestern paths, which in turn represent the Arabian shield geologic province.

The group velocity data were inverted to obtain shear wave velocity structure models of both the shield and the platform regions. Damped least-squares inversions method that utilizes a differential rather than stochastic damping was used to obtain smooth shear wave velocity models. The resulting models are in good agreement with previous results obtained from tomographic inversion.
\end{abstract}

\section{Introduction}

The study of surface wave dispersion had begun independently by Love (1911). Surface wave studies applied to understanding the structure of the earth date from the 1930's with the early work of Gutenberg and Richter (1936). The mod- 
ern era of surface wave dispersion research probably began with the studies of Dziewonski et al. (1969) and Knopoff (1972). Most current dispersion studies are little different from those in the 1970's, excepting the utilization of more powerful computers and algorithms, the vastly-improved instrumentation, the better path coverage across most regions of interest, as well as the very high quality digital seismic data.

The purpose of this study is to use data from a number of stations located on the Arabian peninsula to characterize the seismic wave propagation across the Arabian plate using very high quality broadband digital seismic data signals from within the plate. The Arabian plate is characterized by diverse seismotectonic environments and plate boundaries (Barazangi, 1981). Very little is known, however, about the characteristics and variations of its physical properties.

Most of the previous studies that are related to the crust of this plate are based upon narrow band data such as those obtained from seismic refraction profiles (e.g. Drake and Girdler, 1964; Blank et al., 1979; Healy et al., 1982; Makris et al., 1984; Prodhel, 1985; Mooney et al., 1985; Mechie et al., 1986; and Badri, 1991). The other main source of information for studying the crust is the data from surface waves. Analysis of these data was either restricted to short periods (e.g. Mokhtar et al., 1988) or consisted of narrow band surface waves recordings of regional and teleseismic earthquakes (e.g. Niazi, 1968; Knopoff and Fouda, 1975). These studies did not reveal details of the variations of the crustal structure of the Arabian plate because the data used were insensitive to variations in the seismic velocities of the crust.

Mokhtar (1987) and Mokhtar et al. (1988) used short period Rayleigh waves recorded by a deep seismic refraction profile along a $1000 \mathrm{~km}$ line that traverses the Arabian shield to invert for the shallow structure of the Arabian shield. It was found that the shear wave velocity in the shield increases from $2.6 \mathrm{~km} / \mathrm{s}$ to $3.4 \mathrm{~km} / \mathrm{s}$ in the upper $400 \mathrm{~m}$ of the crust.

In addition, recent work using data from RIYD station and other WWSSN stations in the region gave preliminary results about the nature of the shear wave velocity structure of the crust (Seber and Mitchell, 1992; Ghalib, 1992; and Mokhtar and Al-Saeed, 1994). Again, only narrow band data were used in these studies. The first attempt, however, to study the crust using data from within the plate itself was that of Mokhtar and Al-Saeed (1994). They used data records from RYD station, which lies near the middle of the Arabian plate. The results of this study showed that the average shear wave velocity of the crust of the Arabian shield is higher than that of the Arabian platform and is about 3.61 $\mathrm{km} / \mathrm{s}$ for the upper crust and $3.88 \mathrm{~km} / \mathrm{s}$ for the lower crust, and the total crustal 
thickness is about $40 \mathrm{~km}$. The crustal thickness beneath the platform reaches about $45 \mathrm{~km}$, and its upper and lower crust velocities are $3.24 \mathrm{~km} / \mathrm{s}$ and $3.4 \mathrm{~km} / \mathrm{s}$, respectively.

Ghalib (1992) used dispersion data from earthquakes surrounding the Arabian plate to invert for shear wave velocities using a two dimensional grid of $3^{\circ} \times 3^{\circ}$. He concluded that the seismic velocity of the crust is highest under the shield, but below $40 \mathrm{~km}$ depth it is lower than the rest of the plate. Ghalib (1992) also presented maps showing the variations of the shear wave velocity beneath the Arabian plate. Mokhtar et al. (1999) and Mokhtar et al. (2001) investigated the group velocity distribution beneath the Arabian plate using tomographic inversion of surface waves dispersion data to produce maps showing group velocity variations across the Arabian plate. Their results showed that systematic differences were observed in the distribution of short period velocities between the shield and the platform areas, with higher S-wave velocity in the shield area.

\section{Dispersion of Surface Waves across Arabia}

In this study, the group velocities of both Love and Rayleigh waves were studied along several different path groups. Each single path consists of the sigment of the great circle that transects the epicenter and the station used. Several epicenters to receiver paths are considered. They can be grouped according to their direction of propagation and the geological provinces traversed by the great circle path into 6 different paths. These are the eastern, northeastern, northwestern, Gulf of Aqaba, southwestern, and southeastern paths (Fig. 1).

A total of nine broadband temporary stations were deployed across the Arabian shield to collect very high quality waveform data and the associated parametric data describing the sources over a period of one year and three months (Vernon and Berger, 1998). These stations consisted of STS-2 seismometers recording continuously on REFTEK data loggers. The experiment was conducted as an effort to locate the best sites with respect to properties of detection thresholds and ground noise level. The data from these nine stations suggest the sites in the Arabian shield to be among the best sites in the world and that they are extremely quiet. The temporary deployment station codes, coordinates, and names for the sites used are listed in Table (1).

Seismic data recorded by AFIF, HALM, RANI, RAYN, RIYD, and UQSK stations for a number of earthquakes that took place in southern and northwestern Iran, northern Arabia, the Gulf of Aqaba, the middle and southern Red Sea, and the Gulf of Aden were used. These events are listed in Table (2). The paths were carefully chosen in order that the total or, at least, the major part of the length of each path would lie within either the shield or the platform. 
EAST

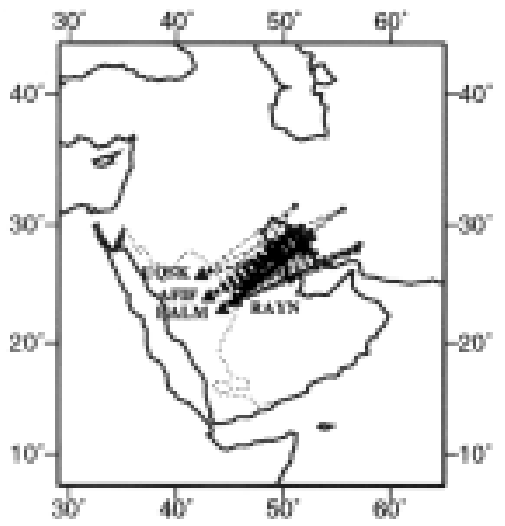

NORTHWEST

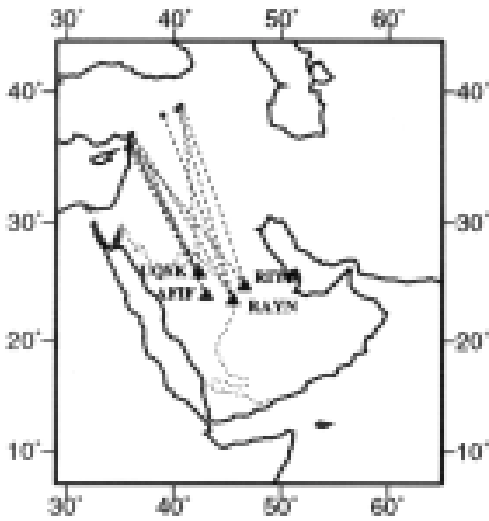

SOUTHWEST

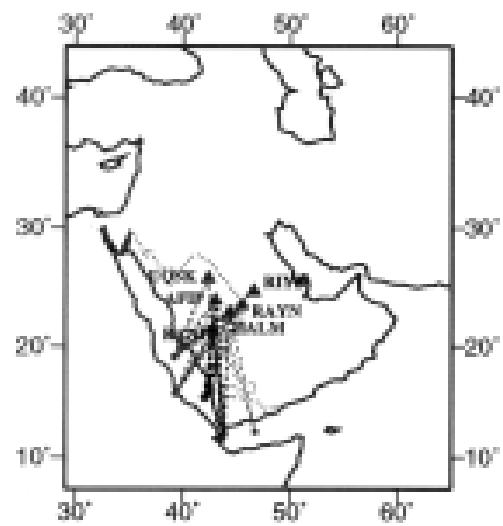

NORTHEAST

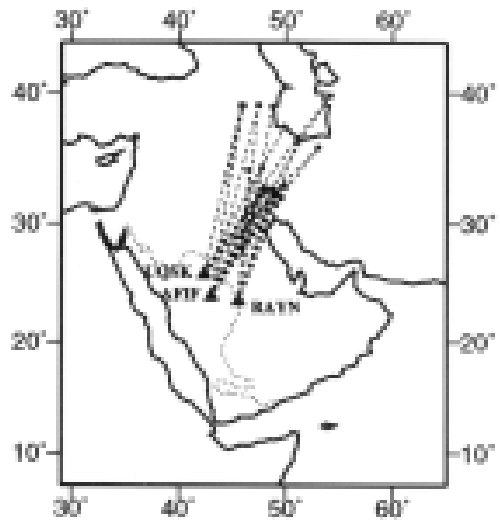

GULF OF AQABA

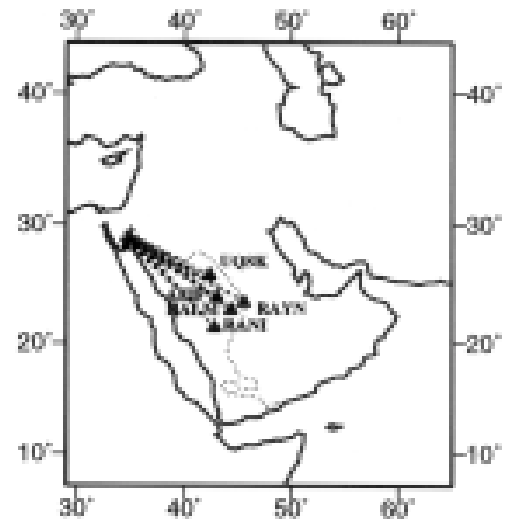

SOUTHEAST

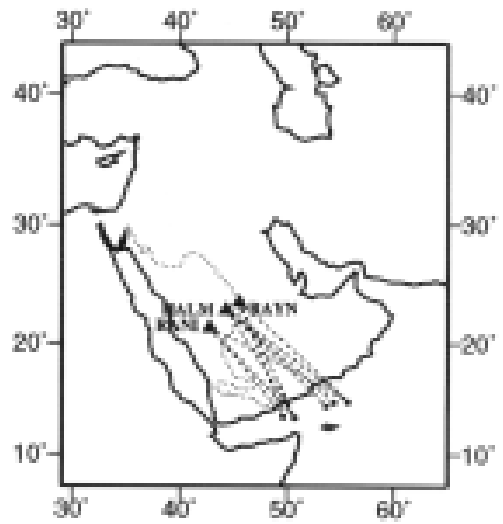

FIG. 1. Maps showing the six different propagation paths from the locations of the earthquakes used in each path to the seismic stations at which data were available for these events. 
TABLE 1. Station codes, coordinate, and names for the sites used in the Saudi Arabian broadband deployment (Vernon and Berger, 1998).

\begin{tabular}{|l|c|c|c|c|}
\hline Station name & Latitude $^{\mathrm{o}}$ & Longitude $^{\mathrm{o}}$ & Elevation $(\mathrm{km})$ & Location in Saudi Arabia \\
\hline AFIF & 23.9310 & 43.0400 & 1.1160 & Afif \\
BISH & 19.9228 & 42.6901 & 1.3790 & Bisha \\
HALM & 22.8454 & 44.3173 & 0.9300 & Hadabat Al-Mahri \\
RANI & 21.3116 & 42.7761 & 1.0010 & Raniyah \\
RAYN & 23.5220 & 45.5008 & 0.7920 & Ar-Rayn \\
RIYD & 24.7220 & 46.6430 & 0.7170 & Riyadh \\
SODA & 18.2921 & 42.3769 & 2.8760 & Al-Soda \\
TAIF & 21.2810 & 40.3490 & 2.0500 & Taif \\
UQSK & 25.7890 & 42.3600 & 0.9500 & Uqlat as Sugur \\
\hline
\end{tabular}

TABLE 2. Parameters of the earthquakes used in this study.

\begin{tabular}{|c|c|c|c|c|c|c|c|c|c|}
\hline \multicolumn{2}{|c|}{ Date } & \multicolumn{4}{|c|}{ Origin time } & \multicolumn{4}{|c|}{ Hypocenter } \\
\hline Y & M & $\mathrm{D}$ & $\mathrm{H}$ & M & $\mathrm{S}$ & Latitude $^{o}$ & Longitude $^{o}$ & $\begin{array}{c}\mathrm{H} \\
(\mathrm{km})\end{array}$ & $\begin{array}{c}\text { Magnitude } \\
\mathrm{mb}\end{array}$ \\
\hline \multirow[t]{2}{*}{1995} & 12 & 31 & 10 & 53 & 00.92 & 29.42 & 52.38 & 33 & 4.30 \\
\hline & 12 & 31 & 11 & 56 & 39.55 & 29.39 & 52.44 & 33 & 4.70 \\
\hline \multirow[t]{26}{*}{1996} & 01 & 02 & 19 & 14 & 40.76 & 28.71 & 34.30 & 10 & 4.60 \\
\hline & 01 & 03 & 08 & 42 & 25.75 & 38.99 & 48.72 & 56 & 5.40 \\
\hline & 01 & 03 & 10 & 05 & 28.60 & 28.71 & 34.94 & 10 & 5.00 \\
\hline & 01 & 04 & 10 & 31 & 41.73 & 32.13 & 49.44 & 33 & 4.80 \\
\hline & 01 & 04 & 14 & 24 & 41.59 & 28.69 & 34.76 & 10 & 4.40 \\
\hline & 01 & 04 & 15 & 28 & 36.61 & 35.46 & 39.56 & 10 & 4.60 \\
\hline & 01 & 04 & 16 & 25 & 32.47 & 28.69 & 34.71 & 10 & 4.30 \\
\hline & 01 & 04 & 17 & 22 & 39.56 & 28.72 & 34.74 & 10 & 4.30 \\
\hline & 01 & 04 & 17 & 34 & 48.22 & 28.68 & 34.68 & 10 & 4.30 \\
\hline & 01 & 06 & 07 & 36 & 09.48 & 28.89 & 34.94 & 10 & 4.40 \\
\hline & 01 & 08 & 13 & 18 & 25.08 & 29.25 & 34.73 & 10 & 4.40 \\
\hline & 01 & 14 & 20 & 05 & 24.09 & 36.59 & 51.15 & 33 & 4.00 \\
\hline & 01 & 18 & 21 & 14 & 34.80 & 10.11 & 56.71 & 24 & 5.10 \\
\hline & 01 & 24 & 05 & 28 & 07.41 & 29.50 & 51.02 & 44 & 4.50 \\
\hline & 01 & 24 & 06 & 05 & 26.03 & 29.36 & 51.01 & 34 & 4.50 \\
\hline & 01 & 25 & 18 & 05 & 21.51 & 29.30 & 51.01 & 48 & 4.70 \\
\hline & 01 & 26 & 13 & 11 & 13.85 & 29.34 & 51.01 & 33 & 4.60 \\
\hline & 01 & 26 & 19 & 01 & 28.73 & 28.75 & 52.38 & 33 & 4.40 \\
\hline & 01 & 28 & 08 & 43 & 16.36 & 34.27 & 46.46 & 33 & 4.90 \\
\hline & 02 & 20 & 08 & 36 & 46.71 & 15.77 & 39.21 & 33 & 4.50 \\
\hline & 02 & 21 & 04 & 59 & 53.45 & 28.88 & 34.75 & 22 & 5.40 \\
\hline & 02 & 26 & 07 & 17 & 28.31 & 28.73 & 34.82 & 23 & 5.00 \\
\hline & 02 & 26 & 08 & 08 & 19.20 & 28.28 & 57.06 & 32 & 5.50 \\
\hline & 03 & 07 & 10 & 03 & 54.48 & 13.43 & 49.69 & 10 & 4.20 \\
\hline & 03 & 08 & 01 & 48 & 56.29 & 28.06 & 51.95 & 33 & 4.10 \\
\hline & 03 & 13 & 08 & 05 & 30.01 & 28.87 & 51.61 & 33 & 4.00 \\
\hline
\end{tabular}


TABLE 2. Continued.

\begin{tabular}{|c|c|c|c|c|c|c|c|c|c|}
\hline \multicolumn{2}{|c|}{ Date } & \multicolumn{4}{|c|}{ Origin time } & \multicolumn{4}{|c|}{ Hypocenter } \\
\hline Y & M & $\mathrm{D}$ & $\mathrm{H}$ & M & S & Latitude $^{o}$ & Longitude $^{\mathrm{o}}$ & $\begin{array}{c}\mathrm{H} \\
(\mathrm{km})\end{array}$ & $\begin{array}{l}\text { Magnitude } \\
\mathrm{mb}\end{array}$ \\
\hline & 03 & 14 & 21 & 47 & 58.86 & 14.74 & 55.74 & 10 & 5.20 \\
\hline & 03 & 16 & 20 & 18 & 33.05 & 29.32 & 51.03 & 33 & 4.30 \\
\hline & 03 & 16 & 20 & 21 & 41.59 & 29.41 & 50.89 & 33 & 4.00 \\
\hline & 03 & 18 & 03 & 11 & 42.71 & 29.48 & 51.01 & 33 & 4.00 \\
\hline & 03 & 20 & 01 & 54 & 53.76 & 28.40 & 51.41 & 41 & 3.90 \\
\hline & 03 & 20 & 11 & 48 & 41.74 & 36.91 & 36.01 & 10 & 3.90 \\
\hline & 03 & 20 & 22 & 24 & 04.48 & 29.47 & 50.99 & 33 & 4.50 \\
\hline & 03 & 23 & 04 & 02 & 11.37 & 28.88 & 52.77 & 33 & 4.30 \\
\hline & 03 & 27 & 03 & 33 & 47.75 & 28.74 & 52.00 & 33 & 4.00 \\
\hline & 03 & 28 & 07 & 28 & 28.12 & 11.92 & 57.81 & 10 & 5.80 \\
\hline & 03 & 28 & 19 & 24 & 00.23 & 13.29 & 50.76 & 10 & 4.30 \\
\hline & 03 & 28 & 19 & 27 & 12.23 & 13.31 & 50.72 & 10 & 4.50 \\
\hline & 03 & 31 & 15 & 12 & 16.82 & 29.66 & 50.62 & 10 & 4.30 \\
\hline & 03 & 31 & 16 & 02 & 06.07 & 32.05 & 49.47 & 33 & 4.30 \\
\hline & 03 & 31 & 21 & 13 & 28.20 & 29.77 & 50.51 & 36 & 4.10 \\
\hline & 04 & 01 & 14 & 20 & 52.77 & 29.50 & 50.83 & 33 & 4.20 \\
\hline & 04 & 01 & 16 & 51 & 40.44 & 29.68 & 50.68 & 33 & 4.20 \\
\hline & 04 & 02 & 10 & 41 & 24.28 & 29.43 & 51.71 & 33 & 3.90 \\
\hline & 04 & 07 & 05 & 57 & 52.75 & 15.70 & 42.33 & 10 & 4.10 \\
\hline & 04 & 08 & 02 & 20 & 43.51 & 38.23 & 38.98 & 10 & 3.80 \\
\hline & 04 & 09 & 17 & 38 & 23.61 & 28.17 & 56.86 & 33 & 4.00 \\
\hline & 04 & 10 & 21 & 50 & 43.05 & 28.13 & 56.74 & 33 & 4.70 \\
\hline & 04 & 11 & 20 & 00 & 12.24 & 32.49 & 49.03 & 33 & 3.80 \\
\hline & 04 & 15 & 14 & 10 & 42.58 & 26.59 & 54.38 & 33 & 4.00 \\
\hline & 04 & 18 & 20 & 13 & 04.50 & 27.86 & 56.87 & 33 & 4.00 \\
\hline & 04 & 20 & 18 & 30 & 28.23 & 28.06 & 51.87 & 33 & 4.00 \\
\hline & 04 & 22 & 14 & 42 & 32.38 & 39.17 & 47.37 & 29 & 5.00 \\
\hline & 04 & 26 & 15 & 02 & 59.37 & 27.57 & 55.94 & 33 & 3.90 \\
\hline & 04 & 30 & 03 & 41 & 41.24 & 15.29 & 42.05 & 10 & 4.00 \\
\hline & 04 & 30 & 17 & 36 & 09.03 & 15.30 & 42.06 & 10 & 4.10 \\
\hline & 05 & 01 & 11 & 45 & 20.60 & 15.45 & 41.99 & 10 & 4.30 \\
\hline \multirow[t]{12}{*}{1996} & 05 & 02 & 23 & 12 & 17.41 & 15.35 & 42.05 & 10 & 4.30 \\
\hline & 05 & 03 & 17 & 04 & 07.53 & 16.17 & 42.48 & 10 & 3.90 \\
\hline & 05 & 05 & 20 & 42 & 17.48 & 15.46 & 41.92 & 10 & 4.40 \\
\hline & 05 & 06 & 10 & 18 & 11.02 & 32.79 & 48.70 & 33 & 3.80 \\
\hline & 05 & 18 & 20 & 10 & 22.74 & 34.48 & 47.68 & 33 & 3.80 \\
\hline & 06 & 05 & 13 & 13 & 16.23 & 35.82 & 35.66 & 10 & 4.60 \\
\hline & 06 & 16 & 02 & 46 & 00.14 & 12.07 & 43.89 & 10 & 4.40 \\
\hline & 06 & 16 & 04 & 57 & 23.68 & 12.03 & 43.79 & 10 & 4.20 \\
\hline & 06 & 18 & 08 & 11 & 05.73 & 39.16 & 45.80 & 51 & 4.70 \\
\hline & 06 & 18 & 23 & 44 & 11.34 & 36.14 & 35.86 & 10 & 4.40 \\
\hline & 06 & 19 & 00 & 18 & 02.17 & 36.11 & 35.91 & 10 & 4.70 \\
\hline & 06 & 19 & 07 & 07 & 59.83 & 39.12 & 45.94 & 33 & 3.90 \\
\hline
\end{tabular}


TABLE 2. Continued.

\begin{tabular}{|c|c|c|c|c|c|c|c|c|c|}
\hline \multicolumn{2}{|c|}{ Date } & \multicolumn{4}{|c|}{ Origin time } & \multicolumn{4}{|c|}{ Hypocenter } \\
\hline Y & M & D & $\mathrm{H}$ & M & $\mathrm{S}$ & Latitude $^{\circ}$ & Longitude $^{\circ}$ & $\begin{array}{c}\mathrm{H} \\
(\mathrm{km})\end{array}$ & $\begin{array}{c}\text { Magnitude } \\
\text { mb }\end{array}$ \\
\hline & 06 & 23 & 02 & 16 & 41.47 & 12.24 & 46.76 & 10 & 4.20 \\
\hline & 06 & 23 & 15 & 41 & 36.10 & 14.69 & 54.35 & 10 & 4.60 \\
\hline & 06 & 30 & 07 & 40 & 00.26 & 39.00 & 40.64 & 10 & 3.90 \\
\hline & 07 & 01 & 08 & 14 & 46.86 & 28.29 & 52.26 & 33 & 4.30 \\
\hline & 07 & 12 & 19 & 52 & 28.32 & 14.40 & 53.63 & 10 & 4.60 \\
\hline & 07 & 15 & 19 & 31 & 45.55 & 33.06 & 49.84 & 33 & 4.40 \\
\hline & 07 & 16 & 08 & 40 & 46.62 & 32.92 & 47.95 & 33 & 4.10 \\
\hline & 07 & 16 & 16 & 46 & 16.68 & 32.67 & 47.77 & 33 & 4.20 \\
\hline & 07 & 17 & 22 & 12 & 17.88 & 37.51 & 49.84 & 33 & 4.30 \\
\hline & 07 & 18 & 14 & 27 & 57.79 & 31.26 & 55.59 & 33 & 4.00 \\
\hline & 07 & 19 & 02 & 28 & 49.37 & 39.82 & 54.08 & 33 & 5.00 \\
\hline & 07 & 31 & 18 & 46 & 11.76 & 19.08 & 39.16 & 10 & 4.10 \\
\hline & 08 & 06 & 20 & 27 & 19.63 & 27.68 & 53.01 & 33 & 4.80 \\
\hline & 08 & 12 & 23 & 58 & 08.28 & 28.14 & 51.79 & 33 & 4.20 \\
\hline & 08 & 18 & 21 & 20 & 10.29 & 13.06 & 57.94 & 24 & 4.10 \\
\hline & 08 & 24 & 05 & 15 & 56.33 & 31.46 & 51.01 & 33 & 4.40 \\
\hline & 08 & 25 & 00 & 53 & 08.93 & 32.65 & 48.08 & 33 & 4.40 \\
\hline & 08 & 25 & 14 & 17 & 08.28 & 35.96 & 52.95 & 33 & 4.40 \\
\hline & 09 & 02 & 02 & 59 & 04.09 & 11.62 & 43.67 & 10 & 4.30 \\
\hline & 09 & 05 & 04 & 17 & 16.20 & 18.95 & 39.26 & 10 & 4.80 \\
\hline & 09 & 06 & 12 & 36 & 56.20 & 27.81 & 52.42 & 33 & 4.50 \\
\hline & 09 & 15 & 02 & 21 & 10.43 & 29.04 & 35.00 & 10 & 4.20 \\
\hline
\end{tabular}

Group velocities of the fundamental mode of both phases were determined along each path used. The two horizontal components (northern and eastern components) were rotated to obtain the transverse components to determine the Love wave dispersion. The vertical components were used to study Rayleigh waves dispersion. The instrument response was removed from the data and each trace was filtered using band-pass filter to corner frequencies $0.01-1.0 \mathrm{hz}$.

Examples of the vertical, transverse, and radial components of the filtered seismograms used are shown in Fig. (2). This example represents the record of the event that occurred on January 4, 1996 at 10H, 31M, and 41.73S (Table 2). The multiple filter analysis technique (MFT) developed by Dziewonski et al. (1969) was used to determine the fundamental mode group velocity dispersion along each single path. A narrow band-pass filter was used to separate the spectrum of the fundamental mode from the other modes. The employed symmetric Gaussian filter, $H(\omega)$, centered at $\omega=\omega_{0}$, is defined as (Herrmann, 1973):

$$
H(\omega)=\left\{\begin{array}{lc}
\exp \left[\left(-\alpha\left(\omega-\omega_{\mathrm{c}}\right)^{2}\right) / \omega_{\mathrm{c}}^{2}\right] & \omega_{\mathrm{o}}-\omega_{\mathrm{c}} \leq|\omega| \leq \omega_{\mathrm{o}}+\omega_{\mathrm{c}} \\
0 & \text { otherwise }
\end{array}\right\}
$$




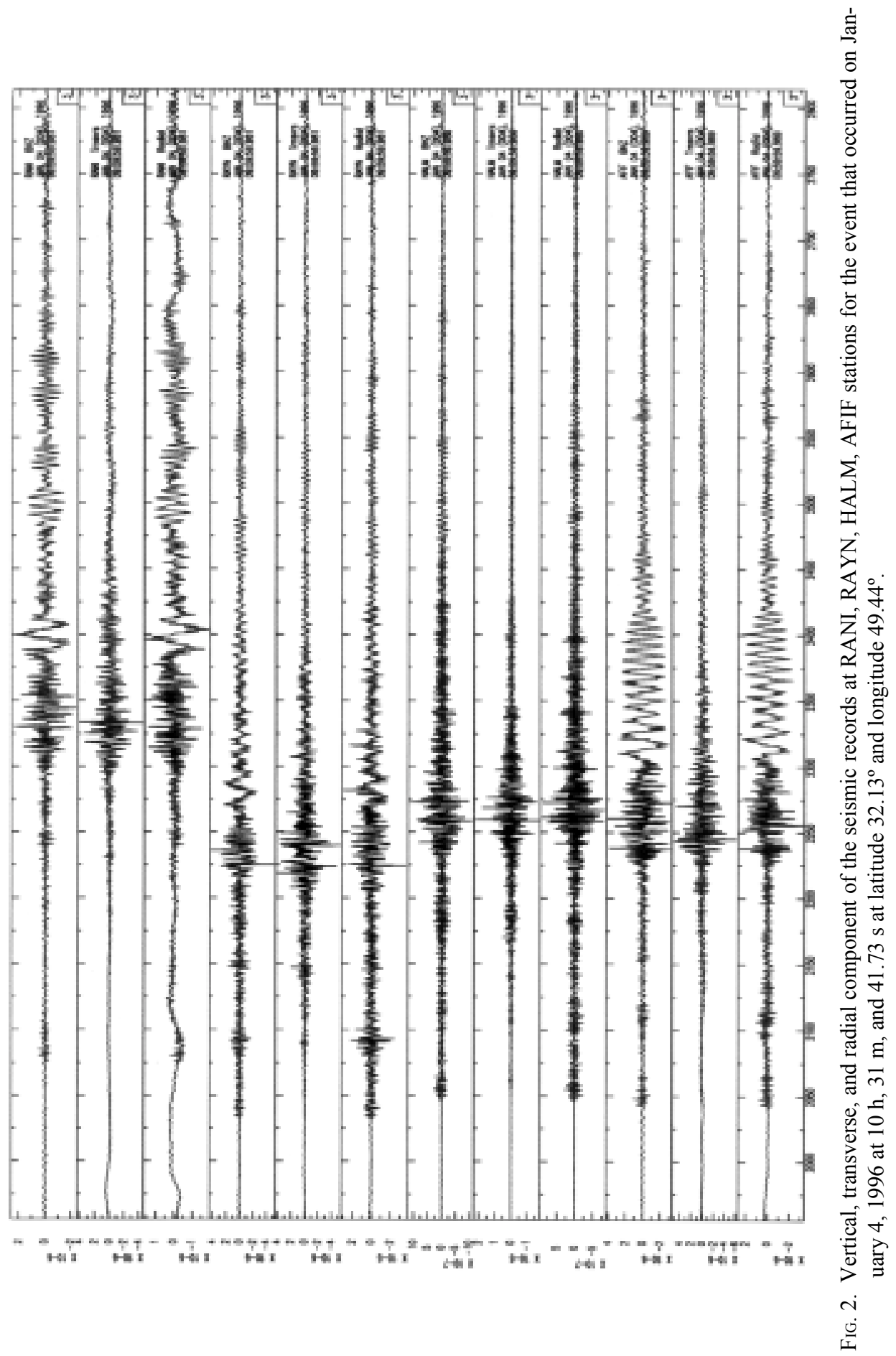


Where

$$
\omega_{\mathrm{c}}=\omega_{\mathrm{o}}(\pi / \alpha)^{1 / 2}
$$

and $\omega_{\mathrm{o}}$ and $\omega_{\mathrm{c}}$ are the filter center and cutoff angular frequencies, respectively. The parameter $\alpha$ controls the filter bandwidth, and hence the filter resolution in the vicinity of each $\omega_{0}$ and velocity value. The result of filtering the input spectra using the above Gaussian filter is a filtered time signal whose envelope reaches a maximum at the group velocity arrival times. The envelope of the filtered time history for a single mode is approximately:

$$
\mathrm{g}(\mathrm{t}, \mathrm{r})=\frac{\mathrm{A} \omega_{\mathrm{O}}}{2 \pi}(\pi / \alpha)^{1 / 2} \exp \left(-\omega_{0}^{2}\left(\mathrm{t}-\mathrm{r} / \mathrm{U}_{\mathrm{o}}\right)^{2} / 4 \alpha\right),
$$

where $U_{0}$ refers to the group velocity, $t$ is the time at which the Gaussian envelope has a maximum amplitude and is given by $\mathrm{t}=\mathrm{r} / \mathrm{U}_{\mathrm{o}}$, and $\mathrm{r}$ is the observation distance.

The envelope is searched for the occurrences of the largest value at each period. Fig. (3) is an example of the output of the MFT analysis. Fig. (3a) shows the fundamental mode spectral amplitude of Rayleigh waves obtained from AFIF vertical component for the even shown in Fig. (2). The epicentral distance for this event from AFIF station is $1106 \mathrm{~km}$. Fig. (3) shows the group velocities at each considered period. The peak spectral amplitude can be correlated to the group velocity value in Fig. (3b). The normalized trace envelopes for each frequency are contoured. At each filter frequency the resulting envelope is normalized to a maximum of 1.0. Contours are drawn at the logarithmic levels of -0.5 , $-0.4,-0.3,-0.2,-0.1$, and 0.0 . The contours represent the envelope of the maximum energy at the various periods as determined by the Gaussian filter of the multiple filter analysis. A band-pass filtered version of the inverse FFT of the input spectra is displayed at the far right. Immediately to the left, the same trace is plotted as amplitude versus apparent velocity. This will make it possible to correlate the group velocity contour values to the trace itself.

As shown in the example of Fig. (3), the highest amplitudes of the fundamental mode spectral values are observed for periods between 5 and $20 \mathrm{sec}$ onds. The amplitude decreases for higher periods until it reaches a minimum at about 70 seconds period. The corresponding group velocities of the fundamental mode can be picked up from the group velocity plot for this period range. However, the values for periods longer than 60 seconds could not be trusted due to their very low amplitudes. In general, the period range for which there are reliable observations for the epicentral distances considered is less than 60 seconds. 

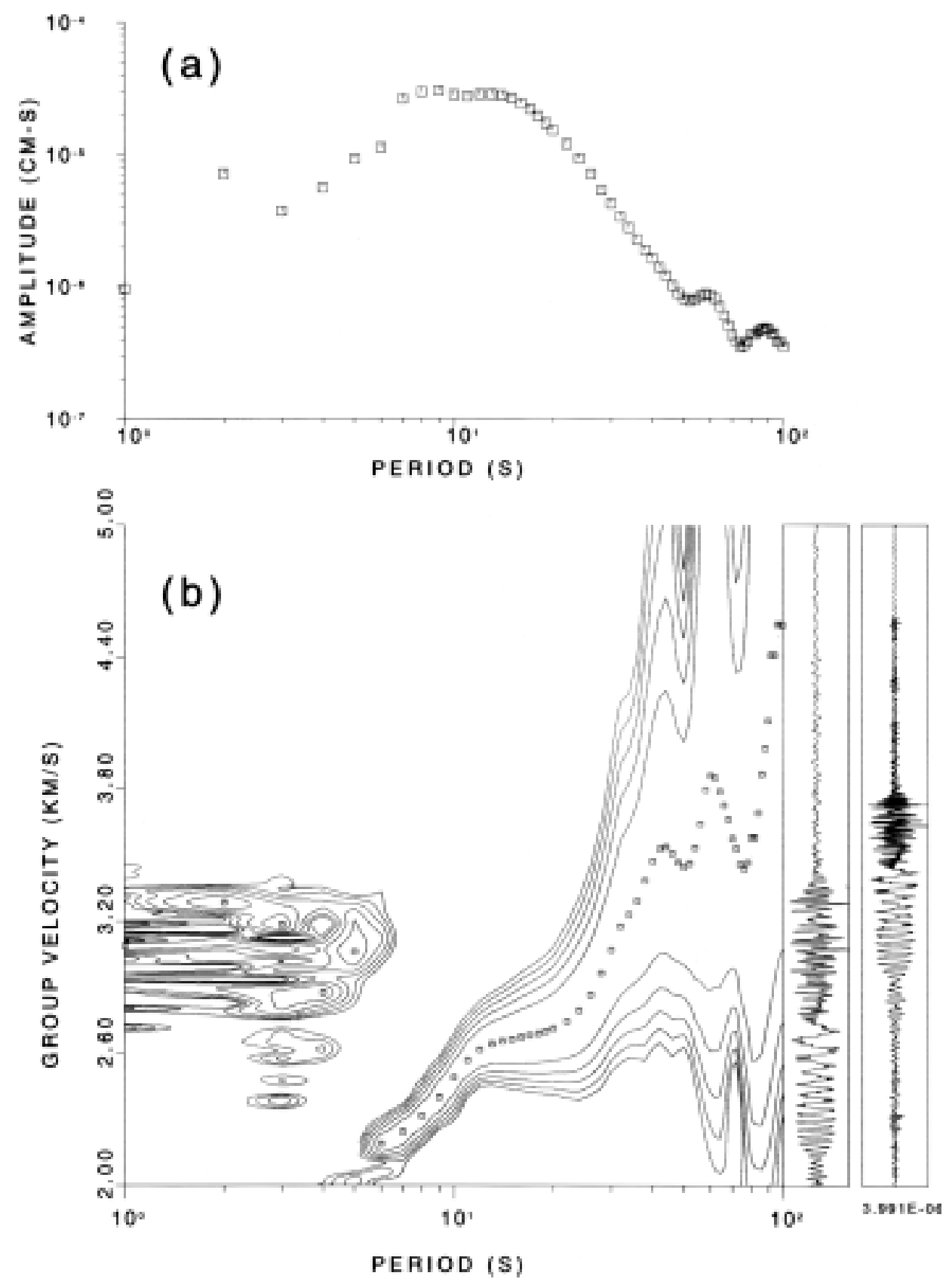

FIG. 3. An example of the output of the MFT performed on AFIF vertical component for the event shown in Fig. (2). (a) The amplitude spectrum of the analyzed seismogram. (b) The group velocity contours and the group velocity of the fundamental mode Rayleigh waves. 


\section{Shear Wave Velocity Inversion}

The purpose of inversion is to extract information, which involves the estimation of the physical parameters of a postulated model from a set of observations. Typically, the linear least squares problem is presented according to the following formulation:

$$
\mathrm{Y}=\mathrm{Ax}+\varepsilon
$$

Where $Y$ is an $m \times 1$ vector of observations, $A$ is an $m \times n$ coefficient matrix which relates the model parameters to observations, $x$ is an $n \times 1$ vector of unknown model parameters, $\varepsilon$ is an $m \times 1$ vector of residuals that compensates for the differences between observed and theoretical values. The least-squares solution of the above inverse problem is (Russell, 1987):

$$
\mathrm{x}=\left(\mathrm{A}^{\mathrm{T}} \mathrm{A}+\gamma^{2} \mathrm{I}\right)^{-1} \mathrm{~A}^{\mathrm{T}} \mathrm{Y}
$$

Where the superscript $T$ indicates the transpose of A, I is the Identity matrix, and the damping factor $\gamma$ is a scalar variable to control the instability of poorly constrained problems due to the presence of singular values that approach zero. In practice, solving the above equation is simplified by using the Singular Value Decomposition (SVD) and the matrix (Lawson and Hanson, 1974).

Following Russell (1987) and as a computational approach to inversion, the stochastic (Franklin, 1970) and differential (Twomey, 1977) techniques are usually used to control the instability of $\left(\mathrm{A}^{\mathrm{T}} \mathrm{A}\right)^{-1}$ inverse matrix as a result of the data vector $\mathrm{Y}$ not having enough precision to resolve the model parameters of $\mathrm{x}$. To demonstrate the difference between the two techniques, consider the following generalized expression for the damped linear least-squares method:

$$
\left[\begin{array}{l}
\mathrm{y} \\
0
\end{array}\right]=\left[\begin{array}{l}
\mathrm{A} \\
\gamma \mathrm{F}
\end{array}\right] \mathrm{x}+\left[\begin{array}{l}
\varepsilon \\
\varepsilon_{\gamma}
\end{array}\right]
$$

Where $\mathrm{F}$ is an arbitrary $(\mathrm{n} \times \mathrm{n})$ matrix appended to the original least-squares expression. If $\mathrm{F}=\mathrm{I}$, as in stochastic inversion, equal weights are given to the elements of $\mathrm{x}$ in order to constrain the norm of the solution vector and minimize the function.

In the case of differential inversion, $\mathrm{F}$ is constructed as an upper bidiagonal matrix to constrain the norm of the solution vector gradient. A form of this first order difference weighing matrix is

$$
\mathrm{F}=\left[\begin{array}{cccccc}
1 & -1 & 0 & 0 & . & 0 \\
0 & 1 & -1 & 0 & . & 0 \\
0 & 0 & 1 & -1 & . & 0 \\
\cdot & . & . & . & . & 0 \\
. & . & . & . & 1 & -1 \\
0 & 0 & 0 & 0 & 0 & 1
\end{array}\right]
$$


The inverse of $\mathrm{F}$ is an upper triangular unity matrix and the minimization function is

$$
|\mathrm{y}-\mathrm{Ax}|^{2}+\gamma^{2}|\mathrm{Fx}|^{2}
$$

According to Russell $(1980 ; 1987)$, the first order difference technique gave the optimum solution for surface wave dispersion data. In addition, a single layer starting model gave an unbiased solution to the data. Setting up the linearized surface wave inversion problem involves perturbing Rayleigh and Love wave shear velocity $\beta$, phase velocity $c$, compressional velocity $\alpha$, and media density $\rho$ relative to the shear velocities of an assumed plane layered model. An iterative approach can be used to invert for $\beta$, and the corresponding values of $\alpha$, and $\rho$ can be calculated using Poisson's ratio and the empirical relation between seismic velocities of rocks and density. On the grounds of the aforepresented discussions, the differential inversion approach was adopted in the present investigation.

The inversion of the group velocity data of both Love and Rayleigh waves was performed in this study for each group of paths by using a model consisting of a multilayered model over a half space. Thus, the shear velocity is inverted for using a starting model that consists of several thin layers with varying thickness and constant physical parameters. The thickness of the layers increases with increasing depths. This will ensure that the inverted solution is unbiased by the starting model. I used the model that consists of P-wave velocity $(\alpha)$ of 8.0 $\mathrm{km} / \mathrm{s}$, S-wave velocity $(\beta)$ of $4.6 \mathrm{~km} / \mathrm{s}$, density $(\rho)$ of $3.3 \mathrm{gm} / \mathrm{cm}^{3}$, and Poisson's $(\sigma)$ of $0.25 \cdot \sigma$ is fixed, while, $\alpha, \beta$, and $\rho$ are allowed to vary during the inversion. Several iterations are performed in which the velocity model is updated after each iteration. The inversion process is terminated when the observed dispersion is well matched by the theoretical curve calculated from the inverted model. Fig. (4) illustrates the average group velocities of Love wave and Rayleigh wave fundamental modes (LF and RF, respectively) for the six chosen propagation paths.

Fig. (5) presents the inversion results of the shear wave velocity models plotted for the 6 different paths. Except for the Gulf of Aqaba path model, the velocity increases rapidly from near the surface downward to about $5 \mathrm{~km}$ depth in all other models. The rate of increase of velocity decreases at depths below 5 $\mathrm{km}$. Fig. (6) presents a comparison among the inverted models for all 6 paths. The most striking feature in this comparison is the systematically higher velocity of the upper crust (0-20 km depth) beneath the Gulf of Aqaba, southwest, and southeast paths relative to those of the east, northeast, and northwest paths. This result agrees well with the tomographic inversion results obtained by Mokhtar et al. (1999) and Mokhtar et al. (2001). As far as the near surface de- 

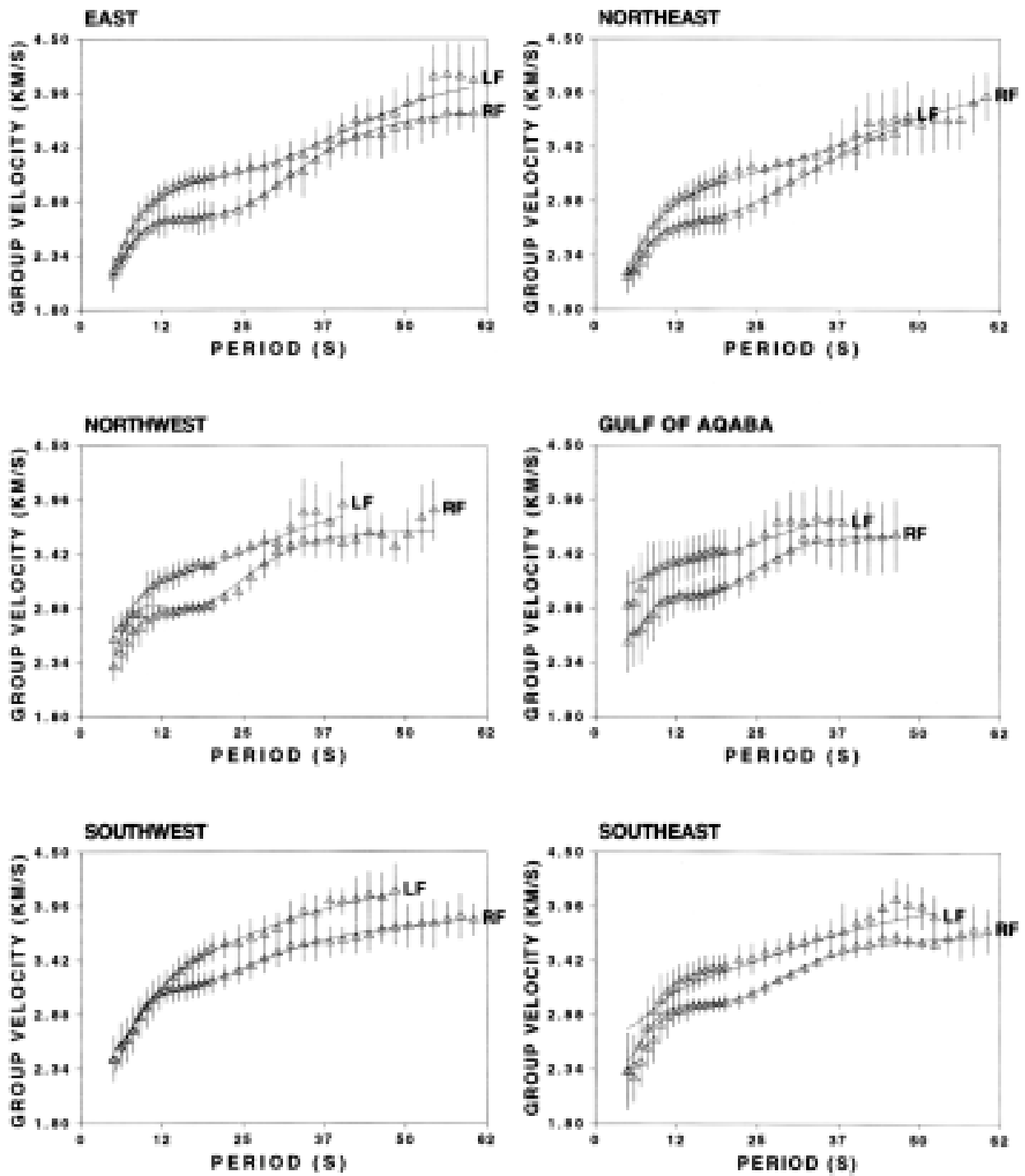

FIG. 4. The average group velocity of Love waves fundamental mode (LF), and Ryleigh waves fundamental mode (RF) for the six different propagation paths used in this study. The lines represent the fitting of the observation using the theoretical dispersion calculated from the inverted models in Fig. (5). 

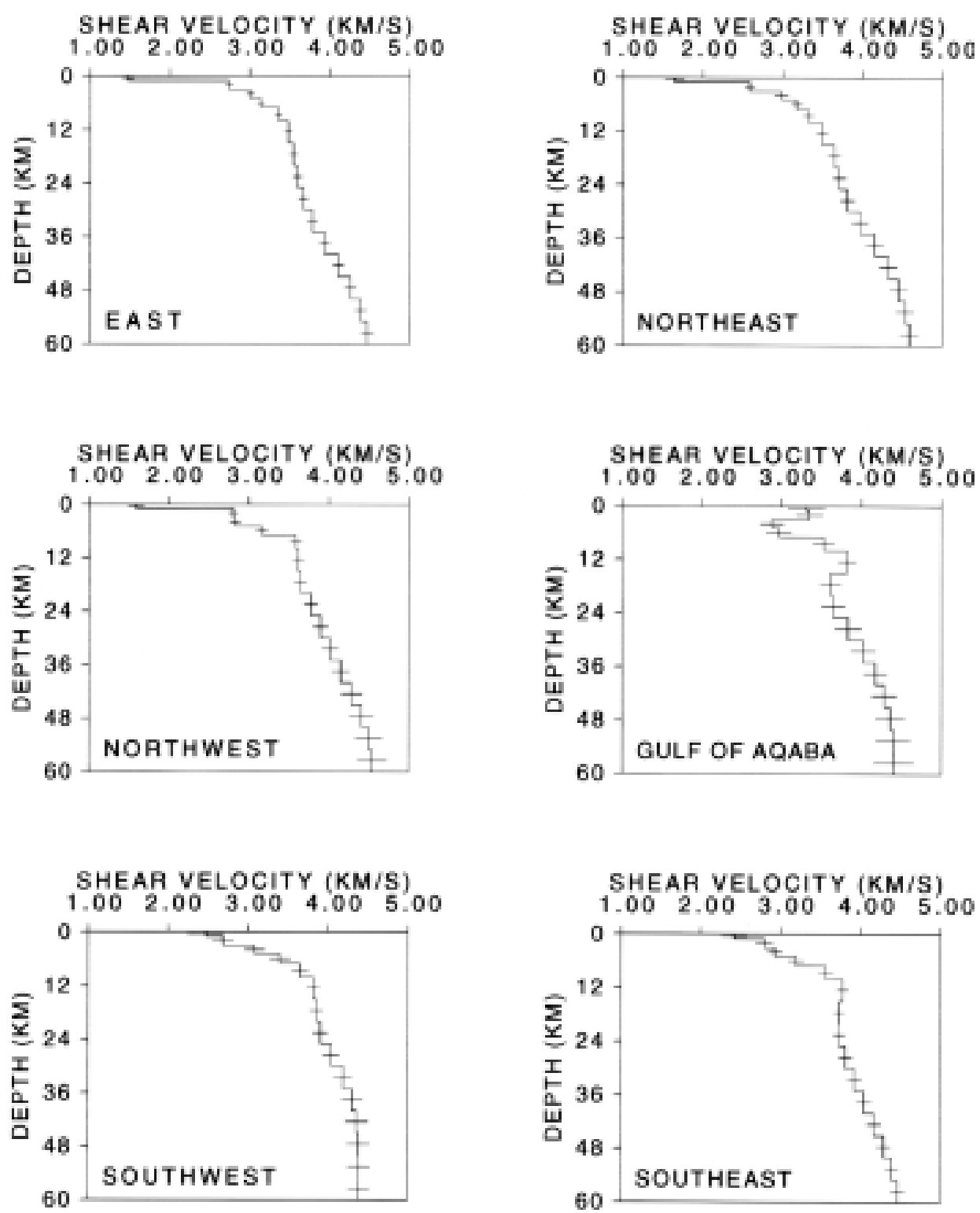

FIG. 5. Inverted shear wave velocity models for the different propagation paths used in this study. 


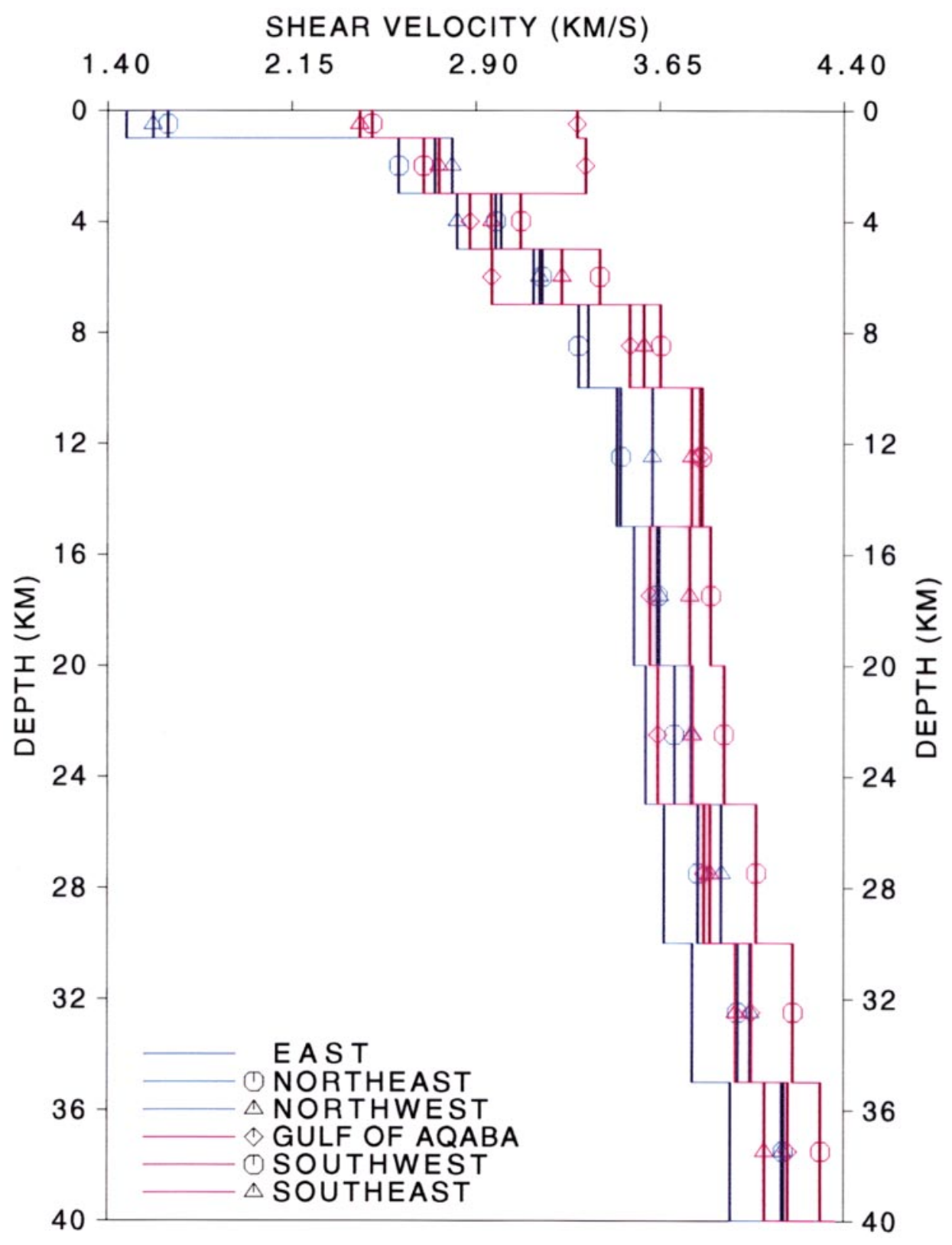

FIG. 6. Comparison amongst all six models of Fig. (5). 
crease of velocity along the Gulf of Aqaba path is concerned, the uncertainties of the data in the short period range do not permit drawing any conclusions from the inverted model.

In order to obtain a simple inverted model for the two geologic provinces, two average dispersion data sets were constructed. Fig. (7) shows the average dispersion curves of both Love and Rayleigh waves of the shield constructed from the data of Gulf of Aqaba, the southwest, and the southeast paths. Fig. (8) presents the average surface wave dispersion of the Arabian platform based on the data from the east, northeast, and northwest paths. The average dispersion curves of both regions are compared with results from the previous study of Mokhtar and Al-Saeed (1994). The group velocities of the Arabian platform in the current study are slightly higher than those of Mokhtar and Al-Saeed (1994). Comparable results are shown for the shield region. The quality of the seismic singles and the increased number of events analyzed in the present study give a greater weight to its findings over that of the previous study.

Each set of the average data sets was inverted independently. A single inversion model has been reproduced for each region based on the average data for each province. The inverted models are presented in Figs. (9) and (10). The Arabian platform consists of the shelf area and the interior platform and sedimentary basins. It covers about two-thirds of the Arabian peninsula and is located east of the shield. The platform consists of Phanerozoic sedimentary rocks that unconformably overly the basement rocks and gently dip to the east towards the Arabian Gulf (Powers et al., 1966). The average velocity of the shield upper crust is systematically higher than that of the platform by about $11-13 \%$. This difference is observed along the whole upper crust. On the other hand, comparable hand, comparable shear velocity exists between 20 to $30 \mathrm{~km}$. The bottom of the lower crust shows again higher velocity below the shield than beneath the platform; however, the difference is less profound in this case (4\%). The resolving kernels from the inversion process are also presented in Figs. (9) and (10). It is obvious that the resolution of the data at hand diminishes rapidly below the upper crust, while there is almost no resolution below the crust (below $\sim 40 \mathrm{~km}$ ).

\section{Discussion and Conclusion}

I have reported the results of a systematic study of broadband Rayleigh and Love wave dispersion data across Arabia. I believe, and argue here, that this study represents a significant contribution to the understanding of surface wave dispersion across this peninsula.

There are three main reasons why I believe that this study represents a significant improvement in the understanding of the dispersion of surface wave 


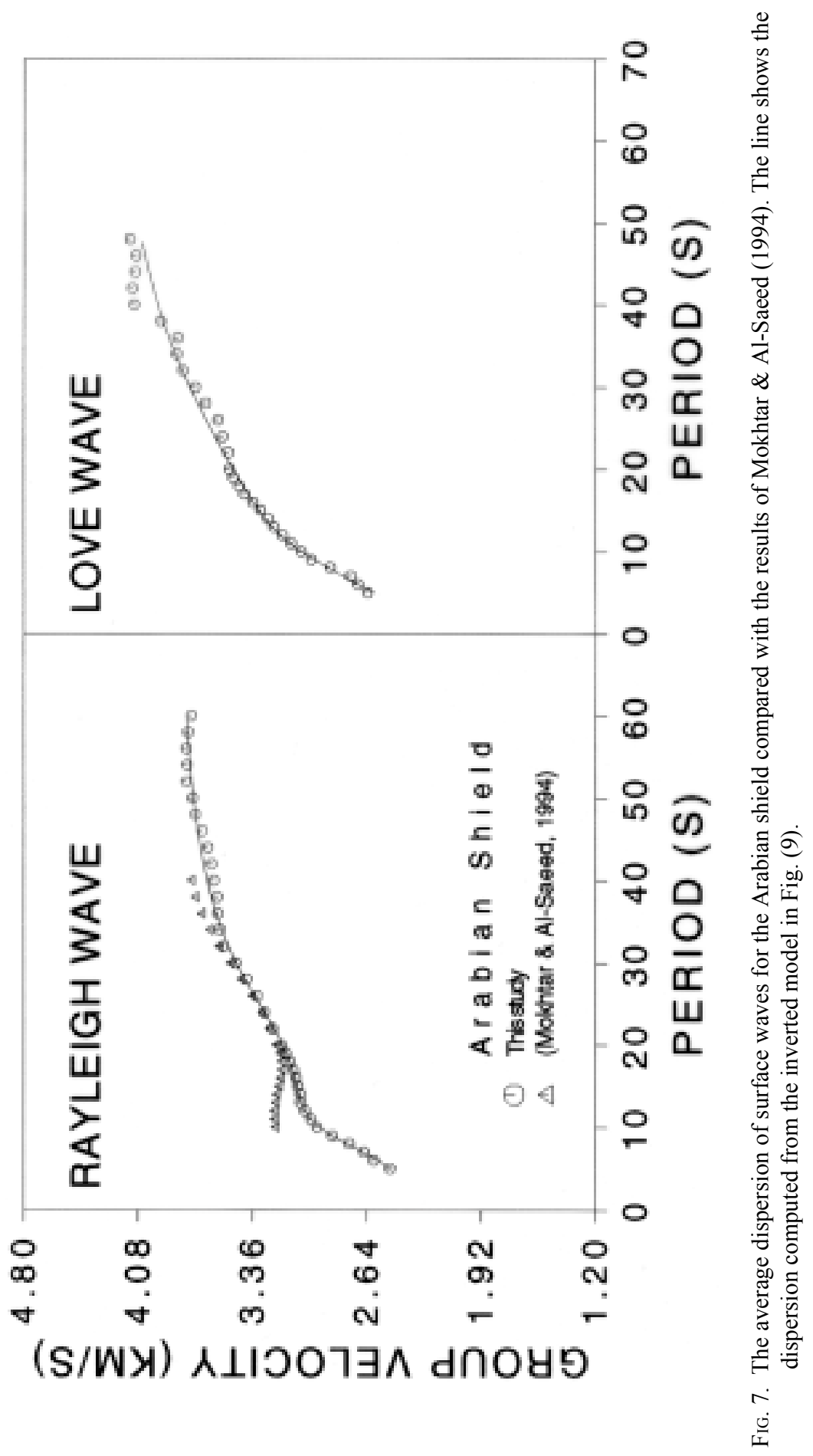




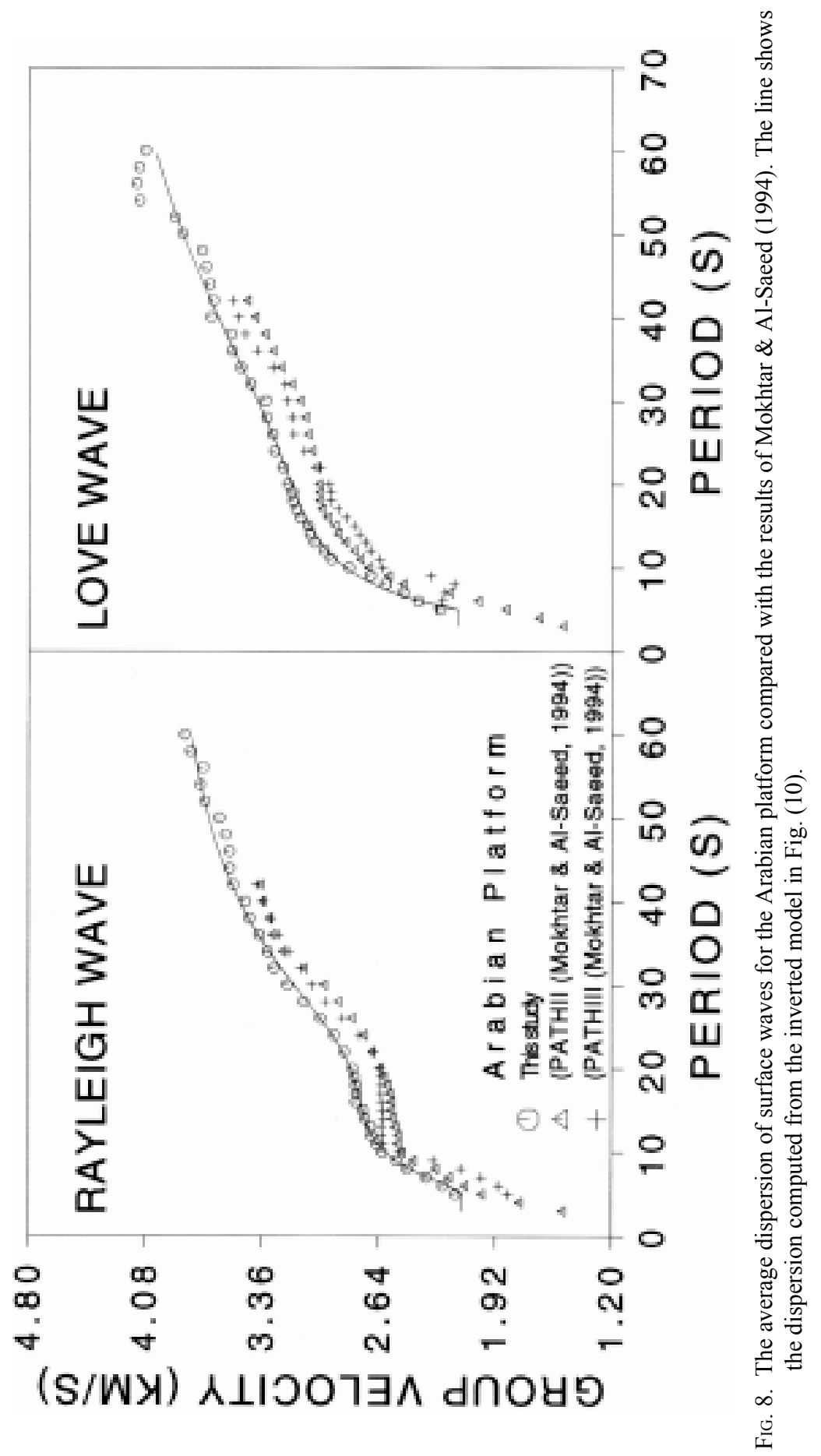




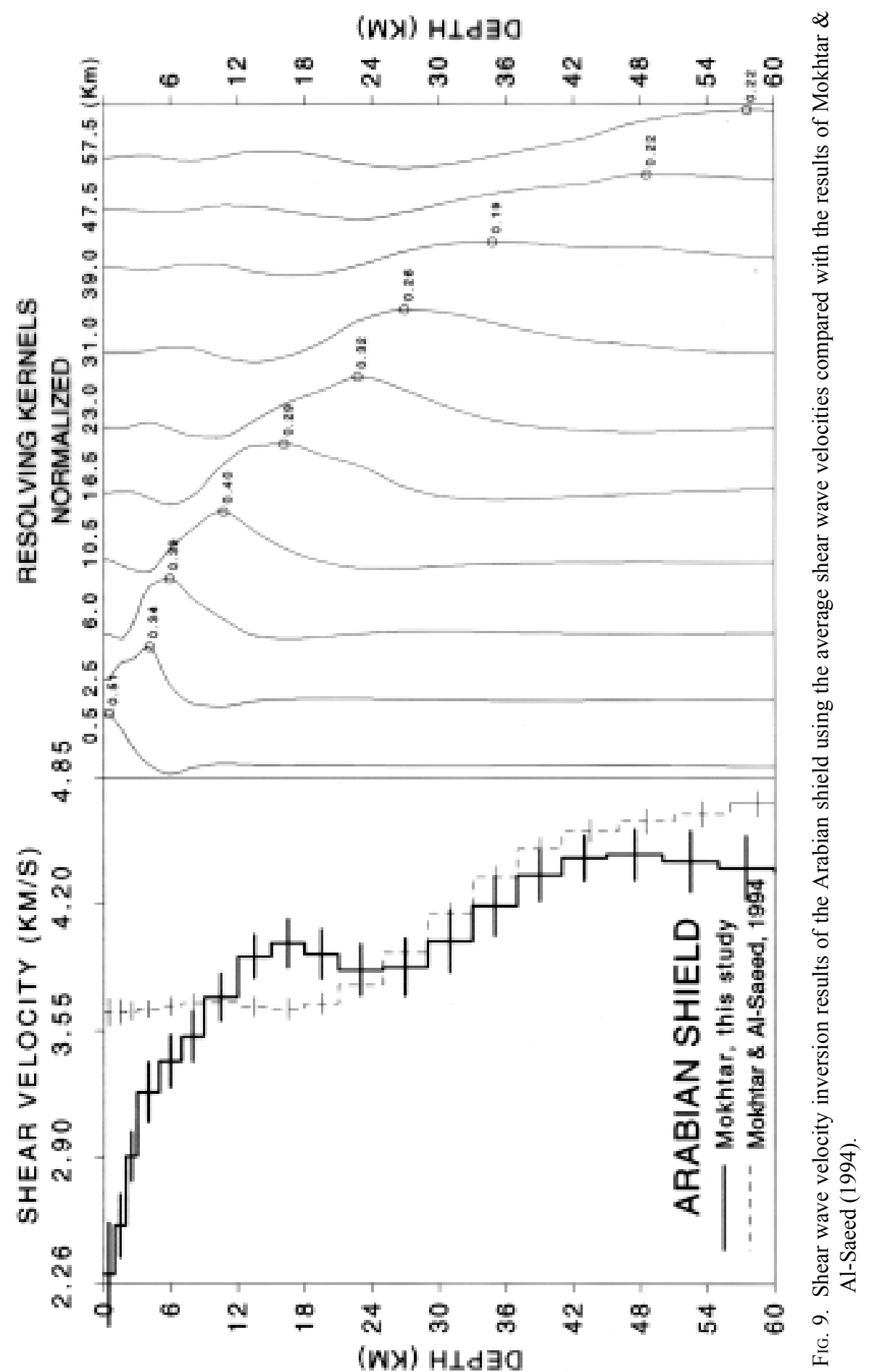




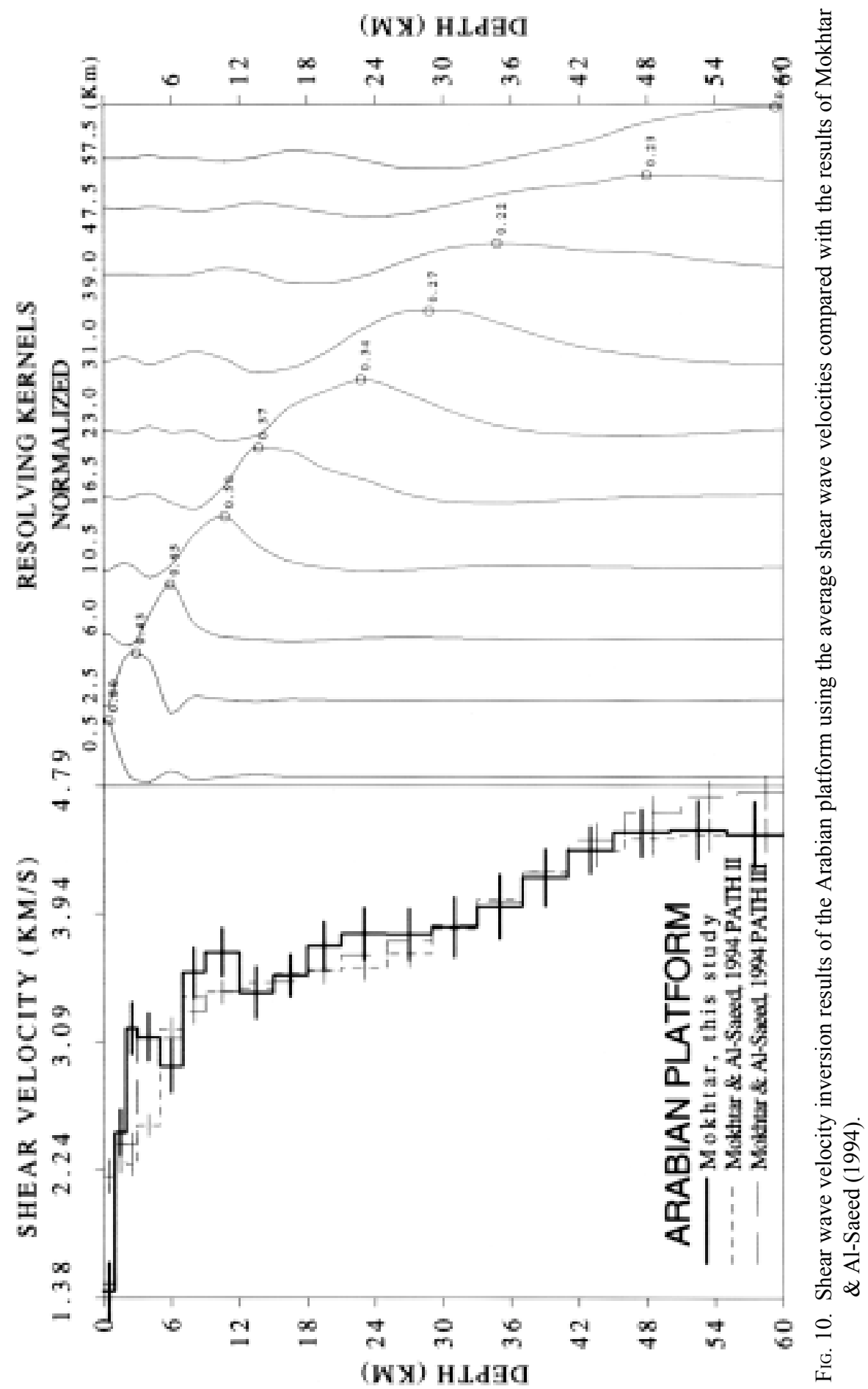


across Arabia. The first has to do with data used. This study is based on very high quality broadband digital data from within the Arabian plate. Second, the use of several sources and receivers combination for each single path covered minimizes the effects of uncertainties of observational errors such as those of origin times, epicentral locations, and finiteness of the source. Finally, the obtained results provide a framework that can be used in future studies that would require azimuthally derived velocity structure in the region for evaluating the attenuation and anisotropy of surface waves in the region.

The main objective of this study is to improve our understanding of the seismotectonic environment of the Arabian plate by investigating the velocity crustal structure of high frequency seismic wave propagation across the region. This was accomplished by calculating surface waves fundamental modes group velocity dispersion along 6 different propagation paths, which are the eastern, northeastern, northwestern, Gulf of Aqaba, southwestern, and southeastern paths. The group velocities of both Rayleigh and Love waves were inverted using a differentially damped least-squares inversion algorithm. The shear wave velocity structures resulting from inversion confirm the previously determined conclusions that the upper crust of the shield is systematically higher in its seismic velocity than the Arabian platform.

The results of inversion are further compared with models prepared by Mokhtar and Al-Saeed (1994). In order to enhance the resolution of the deep structures and to be able to compared the gross features averaged over large depth intervals, I have used each of the above inverted models with many thin layers as a reference from which a simple model of the crust was derived and the inversion process was repeated using this simplified model. Since the surface wave data have less control over the deeper structures, it would have been desirable to fix the velocity of the upper mantle in the inversion process. However, for the purpose of comparing the results with those of Mokhtar and AlSaeed (1994), I followed their method of using the inversion to obtain the velocity of the upper mantle with less emphasis on the confidence of the solution at depth. This comparison is presented in Fig. (11). Although there is in general good agreement between the two studies, improvement is observed for the shield model top $10 \mathrm{~km}$ in the present study. The new models indicate that the crustal shear velocity of both regions is higher than previously estimated, and that the velocity of the upper crust is higher in the shield than in the platform. Similar velocity structures for the lower crust were obtained for both regions. However, as far as the lower crust and upper mantle are concerned, the resolution of the data at hand would only permit drawing conclusions to a depth of about $30 \mathrm{~km}$. Beyond $30 \mathrm{~km}$, the resolution diminishes and the models could only be cautiously interpreted for the lower crust as indicated before. 


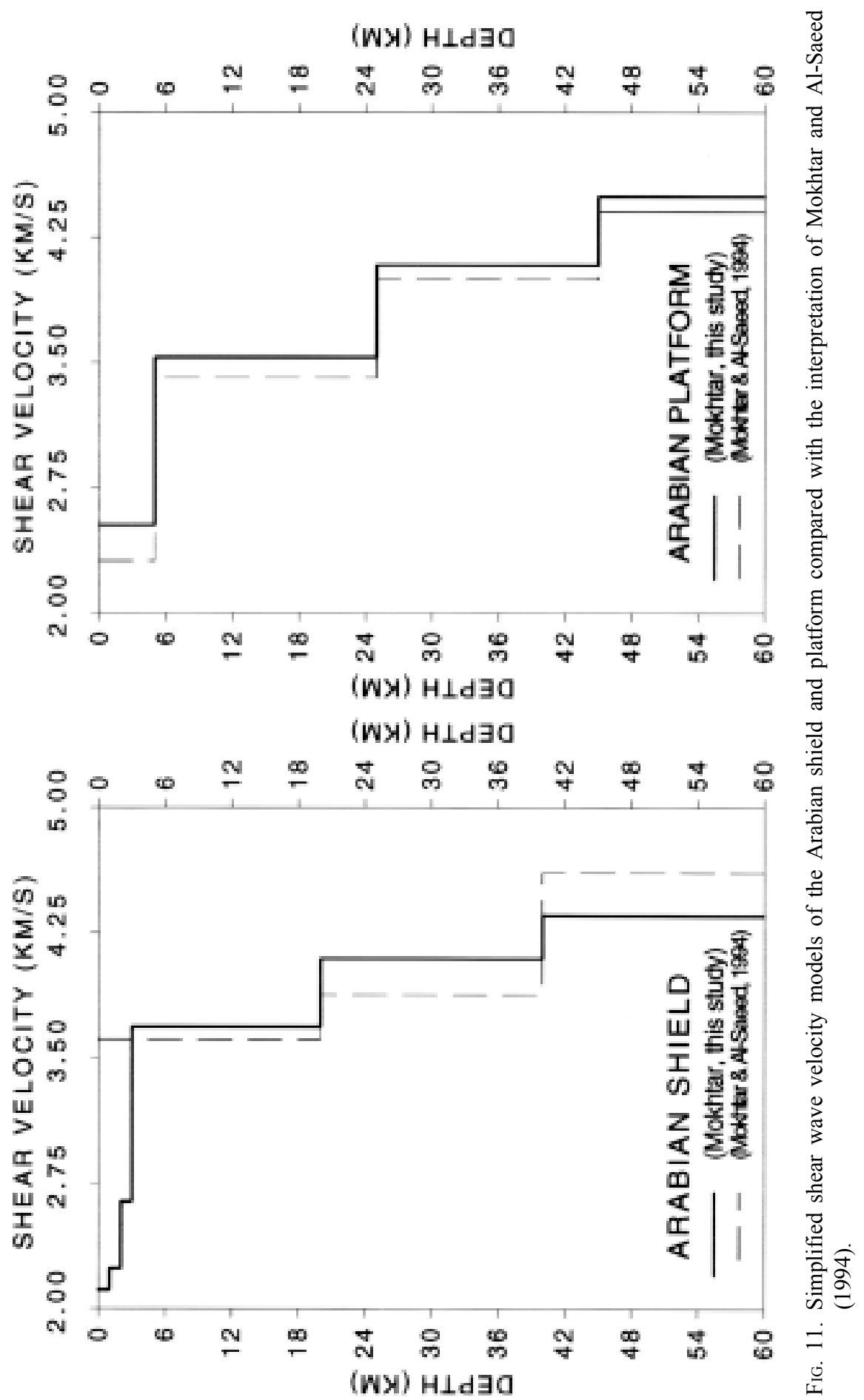


The surface wave velocities in the Arabian shield model presented in this study range from $2.3 \mathrm{~km} / \mathrm{s}$ to $2.91 \mathrm{~km} / \mathrm{s}$ in the upper $3 \mathrm{~km}$ (Table 3). These values do not agree well with the results of Mokhtar (1987) and Mokhtar et al. (1988). The reason for the lower velocities might be the fact that the data used in the latter studies were those of a deep refraction profile that extended along $1000 \mathrm{~km}$ from Riyadh in the northeast to Farasan Island in the Red sea (southeast). The high frequencies of the signal used from this profile permit good resolution of the very shallow structure and might have less control at depth. On the other hand, the longer period of the data of the current study warrants reliable results for the near surface velocities. Also, the results presented in Table (3) were obtained by averaging the dispersion data from three different paths, while the velocities of Mokhtar (1987) and Mokhtar et al. (1988) were based on a single profile and a single direction.

TABLE 3. Inversion models obtained from the average surface waves dispersion.

\begin{tabular}{|c|c|c|c|c|c|}
\hline \multirow{2}{*}{$\begin{array}{l}\text { Layer thickness } \\
\qquad(\mathrm{km})\end{array}$} & \multirow{2}{*}{$\begin{array}{l}\text { Depth to the top of } \\
\text { the layer }(\mathrm{km})\end{array}$} & \multicolumn{2}{|c|}{ Arabian shield model } & \multicolumn{2}{|c|}{ Arabian platform mode } \\
\hline & & $\begin{array}{c}\mathrm{Vp} \\
(\mathrm{km} / \mathrm{s})\end{array}$ & $\begin{array}{c}\mathrm{Vs} \\
(\mathrm{km} / \mathrm{s})\end{array}$ & $\begin{array}{c}\mathrm{Vp} \\
(\mathrm{km} / \mathrm{s})\end{array}$ & $\begin{array}{c}\text { Vs } \\
(\mathrm{km} / \mathrm{s})\end{array}$ \\
\hline 1 & 0 & 3.92 & 2.30 & 2.43 & 1.43 \\
\hline 1 & 1 & 4.34 & 2.55 & 4.22 & 2.48 \\
\hline 1 & 2 & 4.95 & 2.91 & 5.41 & 3.18 \\
\hline 2 & 3 & 5.50 & 3.24 & 5.31 & 3.12 \\
\hline 2 & 5 & 5.78 & 3.39 & 4.98 & 2.92 \\
\hline 2 & 7 & 6.00 & 3.52 & 6.04 & 3.55 \\
\hline 3 & 9 & 6.34 & 3.72 & 6.27 & 3.69 \\
\hline 3 & 12 & 6.70 & 3.93 & 5.81 & 3.41 \\
\hline 3 & 15 & 6.81 & 4.00 & 6.01 & 3.53 \\
\hline 3 & 18 & 6.71 & 3.94 & 6.34 & 3.73 \\
\hline 4 & 21 & 6.57 & 3.86 & 6.48 & 3.81 \\
\hline 4 & 25 & 6.60 & 3.88 & 6.48 & 3.81 \\
\hline 4 & 29 & 6.82 & 4.01 & 6.55 & 3.85 \\
\hline 4 & 33 & 7.13 & 4.18 & 6.79 & 3.99 \\
\hline 4 & 37 & 7.40 & 4.35 & 7.12 & 4.18 \\
\hline 4 & 41 & 7.55 & 4.45 & 7.43 & 4.36 \\
\hline 5 & 45 & 7.58 & 4.45 & 7.63 & 4.48 \\
\hline 5 & 50 & 7.52 & 4.42 & 7.65 & 4.50 \\
\hline 5 & 55 & 7.46 & 4.38 & 7.60 & 4.46 \\
\hline 5 & 60 & 7.43 & 4.37 & 7.61 & 4.47 \\
\hline$\propto$ & 65 & 7.40 & 4.35 & 7.79 & 4.58 \\
\hline
\end{tabular}

Furthermore, comparison of the inverted models with the models obtained via wave form modeling by Rodgers et al. (1999) indicates that there is good agreement between the models obtained for both the shield and the platform regions (Fig. 12). In particular, the shield models show more or less similar shear 


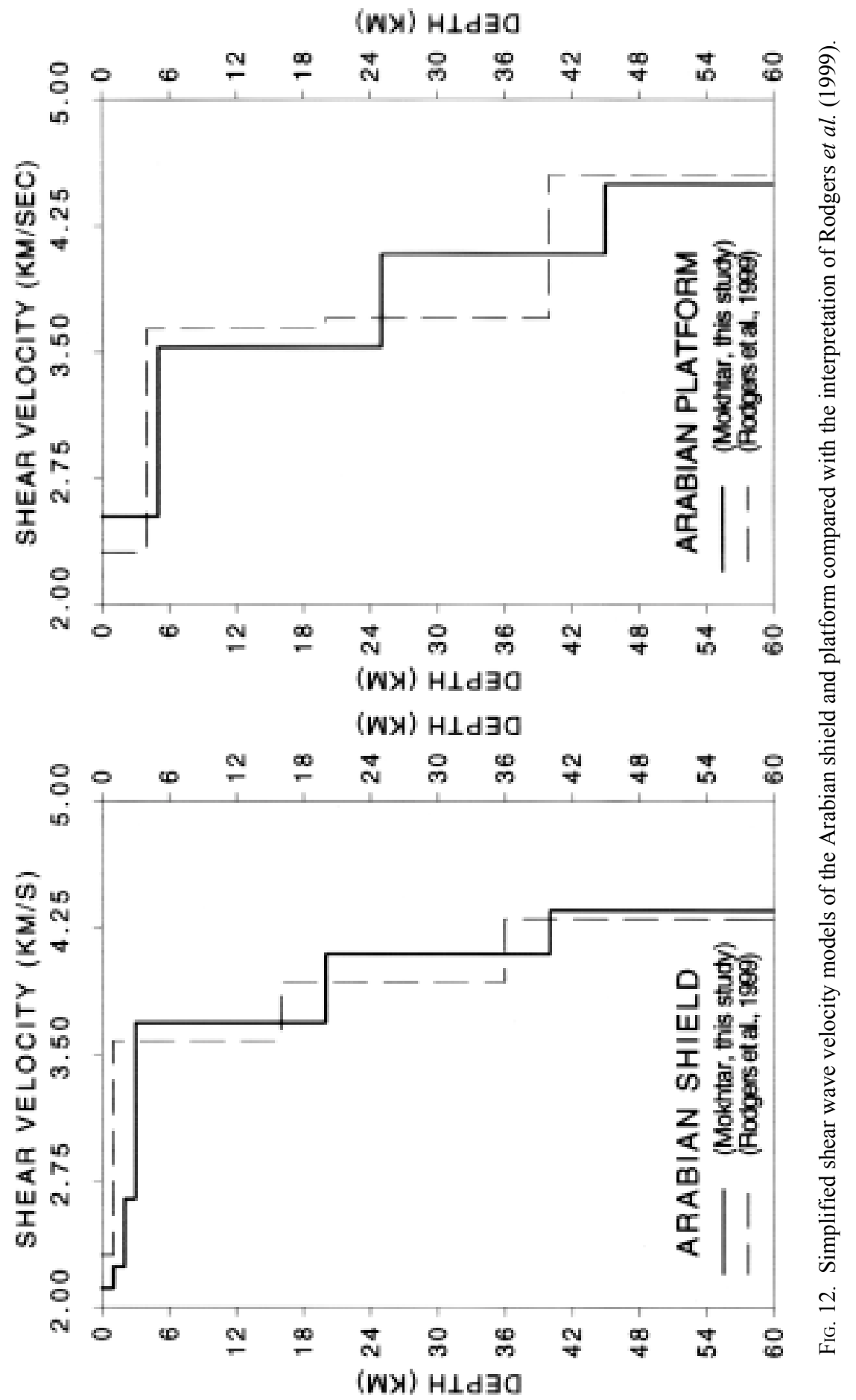


velocity values and the high velocity in the upper crust is clearly modeled by both studies. As far as the platform is concerned, Rodgers et al. (1999) prefer a model in which there is little difference between the shear velocity of the upper and lower crust. This does not agree well with the platform inversion results which clearly show a slightly higher shear velocity for the lower crust and a monotonic increase in shear velocity below $30 \mathrm{~km}$. Although the surface waves data used in both studies do not permit good resolution of the lower crust, further investigations are needed to resolve this discrepancy. Ghalib (1992), however, presented detailed contour maps of the shear wave velocity structure in Arabia. The values of the shear velocities at $35 \mathrm{~km}$ and $40 \mathrm{~km}$ depth beneath the Arabian platform range between 3.9 and $4.1 \mathrm{~km} / \mathrm{s}$ and $4.1-4.2 \mathrm{~km} / \mathrm{s}$, respectively. These values agree well with the results of Mokhtar and Al-Saeed (1994) and this study.

\section{References}

Badri, M. (1991) Crustal structure of central Saudi Arabia determined from seismic refraction profiling. Technophysics, 185: 357-374.

Barazangi, M. (1981) Evaluation of seismic risk along the western part of the Arabian plate: discussion and recommendations. Bull. Fac. Earth Sci., KAAU, 4: 77-87.

Blank, H.R., Healy, J.H., Roller, J.C., Lamson, R., Fischer, F., Mclearn, R. and Allen, S. (1979) Seismic refraction profile, Kingdom of Saudi Arabia - Field operations, instrumentation and Initial Results, U.S. Geological Survey, Saudi Arabian Mission Project Report 259, 49 p.

Drake, C.L. and Girdler, R.W. (1964) A geophysical study of the Red Sea, Geophys. J.R. Astr. Soc., 8: 473-495.

Dziewonski, A.M., Bloch, S. and Landisman, M. (1969) A technique for the analysis of transient seismic signals, Bull. Seism. Soc. Am., 59: 427-444.

Franklin, J.N. (1970) Well-posed stochastic extension of ill-posed linear problems, J. Math. Anal. Appl. 31: 682-716.

Ghalib, H.A.A. (1992) Seismic velocity structure and attenuation of the Arabian plate, Ph.D. Thesis, Saint Louis University, 314 p.

Gutenberg, B. and Richter, C.F. (1936) On seismic waves, Beitr. Geophys., 47: 73-131.

Healy, J.H., Mooney, W.D., Blank, H.R., Gettings, H.R., Kohler, W.M., Lamson, R.J. and Leons, L.E. (1982) Saudi Arabian seismic deep-refraction profile. Final Proj. Rep., Saudi Arabian Deputy Minist. Miner. Resour., Open-file Rep. USGS-OF. 2-37, 429 p.

Hermann, R.B. (1973) Some aspects of band-pass filtering of surface waves. Bull. Seism. Soc. Am., 63: 663-671.

Hermann, R.B. (1985) Surface Waves in Plane Layers, Computer Programs in Seismology, IVII, Saint Louis University, Saint Louis, Missouri.

Jackson, D.D. (1972) Interpretation of inaccurate, insufficient, and inconsistent data, Geophys. J.R. Astron. Soc. 28: 97-109.

Knopoff, L. and Fouda, A.A. (1975) Upper mantle structure under the Arabian Peninsula. Tectonophysics, 26: 121-134.

Lawson, C.L. and Hanson, R.J. (1974) Solving Least-squares Problems. Prentice-Hall, Inc., Englewood Cliffs, New Jersey. 
Love, A.E.H. (1911) Some Problems in Geodynamics, Cambridge University Press (Reprinted 1967, Dover, New York).

Makris, J., Allam, A., Mokhtar, T., Basahel, A., Deghani, G.A. and Bazari, A. (1984) Crustal structure in the northwestern region of the Arabian shield and its transition to the Red Sea, Bull. Fac. Earth Sci., KAAU, 6: 435-447.

Mechie, J., Prodehl, C. and Koptschalitsch, G. (1986) Ray path interpretation of the crustal structure beneath Saudi Arabia. Tectonophysics, 131: 333-352.

Mokhtar, T.A. (1987) Seismic velocity and Q model for the shallow structure of the Arabian shield from short period Rayleigh waves, Ph.D. Thesis, Saint Louis University, Saint Louis, Missouri, USA, $168 \mathrm{p}$.

Mokhtar, T.A., Herrmann, R.B. and Russell, D.R. (1988) Seismic velocity and Q model for the shallow structures of the Arabian shield from short-period Rayleigh waves. Geophysics, 53: $1379-1387$.

Mokhtar, T.A. and M.M. El-Saeed, M.M. (1994) Shear wave velocity structures of the Arabian Peninsula, Tectonophysics, 230: 105-125.

Mokhtar, T.A., Ammon, C.J., Ghalib, H.A. and Herrmann, R.B. (1999) Lithospheric Tomography Structure beneath Arabia using Surface Waves Group Velocities. Journal of King Abdulaziz University: Earth Sciences, 11: 143-160.

Mokhtar, T.A., Ammon, C.J., Hermann, R.B. and Ghalib, H.A. (2001) Surface Wave Velocities Across Arabia, Pure and Applied Geophysics, 158: 1425-1444.

Mooney, W.D., Gettings, M.E., Blank, H.R. and Healy, J. (1985) Saudi Arabian seismic refraction profile: a travel time interpretation of crustal and upper mantle structure, Tectonophysics, 111: 173.

Niazi, M. (1968) Crustal thickness in the Saudi Arabian Peninsula. Geophys. J.R. Astron. Soc., 15: $545-547$.

Prodhel, C. (1985) Interpretation of a seismic refraction survey across the Arabian Shield in western Saudi Arabia, Tectonophysics, 111: 247-282.

Powers, R.W., Ramirez, L.F., Redmond, C.P. and Elberg, E.L. (1966) Geology of the Arabian Peninsula-sedimentary Geology of Saudi Arabia. U.S. Geol. Surv. Prof. Pap., 560-D, 147 p.

Rodgers, A., Walters, W., Mellors, R.J., Al-Amri, A.M.S. and Zhang, Y.S. (1999) Lithosperic structure of the Arabian shield and platform from complete regional waveform modeling and surface wave group velocities, Geophys. J. Inter., 138: 871-878.

Russell, D.R. (1980) Constrained inversion techniques applied to surface wave analysis, M.Sc. Thesis, University of Texas, El Paso, Texas.

Russell, D.R. (1987) Multichannel processing of dispersed surface waves. Ph.D. Thesis, Saint Louis University, Saint Louis, Missouri.

Seber, D. and Mitchell, B. (1992) Attenuation of surface waves across the Arabian peninsula. Tectonophysics, 204: 137-150.

Twomey, S. (1977) Introduction of the Mathematics of Inversion in Remote Sensing and Indirect Measurements, Elsevier Scientific Publishing Co., Amsterdam.

Vernon, F. and Berger, J. (1998) Broadband seismic characterization of the Arabian shield. Final Scientific and Technical Report, Philips Laboratory, 36 p. 


\section{التغيرات في تركيب القشرة الأرضية للجزيرة العربية}

\section{طلال علي مختار}

قسم الجيوفيزياء ، كلية علوم الأرض، جامعة الملك عبدالعزيز مختار

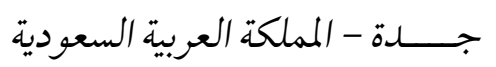

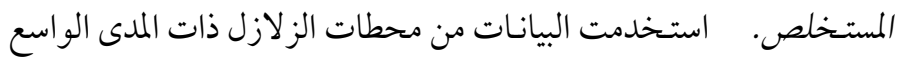

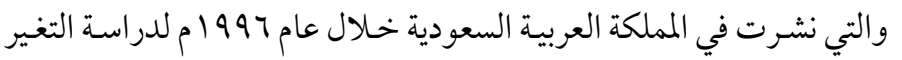

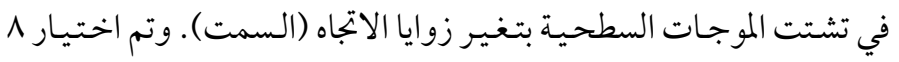

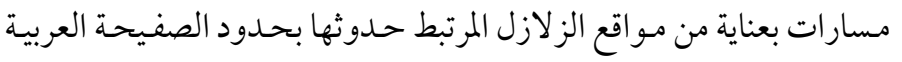

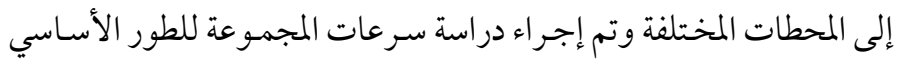
لكل من موجات رايلي وموجات لف. وتدل التتائج على أن الصفيحة العربية

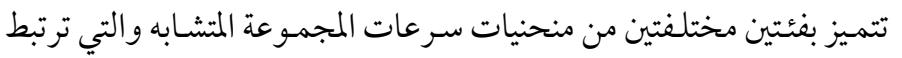

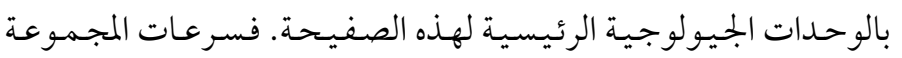

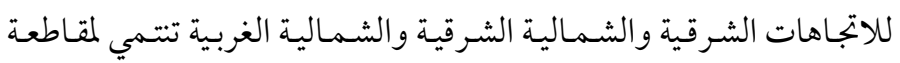

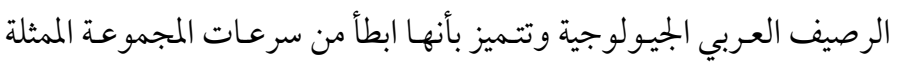

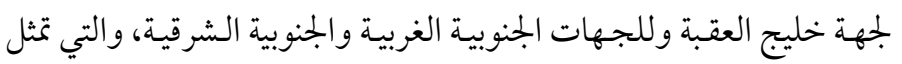
بدورها المقاطعة الجيولوجية للدرع العربي. وتم إجر اء عمليات عكسية لمنحينات سرعات المجموعة لهذه الاتجاهات

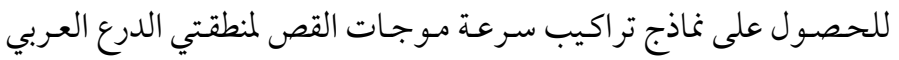

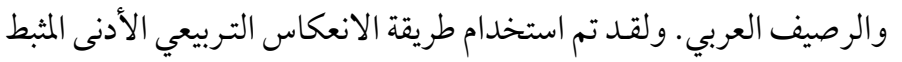

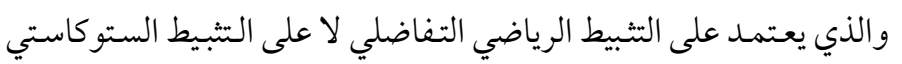

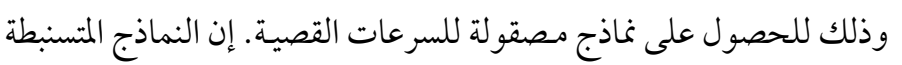

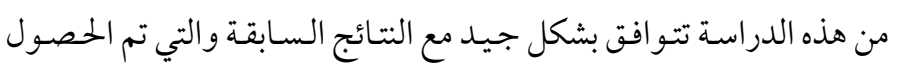
عليها في دراسات سابقة باستخدام الطرق العكسية الطموغرافية. 